\title{
CONFLITOS AMBIENTAIS E DESENVOLVIMENTO RURAL: PROBLEMATIZAÇÃO E USO DE RECURSO AUDIOVISUAL COMO AUXILIO À AÇÃO EXTENSIONISTA
}

José Tobias Marks Machado Universidade Federal do Rio Grande do Sul tobias.machado@hotmail.com

Lucas Woltmann Figueiró Universidade Federal do Rio Grande do Sul lucas.woltmann@ufrgs.br

\section{Resumo}

A implantação da Barragem Marrecas no distrito Vila Seca, em Caxias do Sul, desencadeou um conflito ambiental caracterizado pela sobreposição das formas de ocupação e produção tradicionais. Nesse cenário, o presente artigo se ocupou de dois objetivos: (i) descrever e problematizar disputas que envolvem o barramento; e (ii) construir uma ferramenta de extensão universitária capaz de dar visibilidade o conflito e fortalecer o diálogo. Para tal, visitamos a barragem e realizamos entrevistas não estruturadas com agentes do Serviço Autônomo Municipal de Água e Esgoto, da Secretaria Municipal de Agricultura, Pecuária e Abastecimento e agricultores atingidos, um material analisado à luz de referenciais teóricos pertinentes ao tema de conflitos ambientais e à extensão universitária. Enquanto o primeiro objetivo foi cumprido, o segundo, além do relativo êxito em termos de visibilizar o conflito, esbarrou em limitações de ordem financeira, impossibilitando o acompanhamento e o estímulo à comunicação entre as partes.

Palavras-chave: Desenvolvimento. Questão Ambiental. Extensão Universitária.

\section{ENVIRONMENTAL CONFLICTS AND RURAL DEVELOPMENT: PROBLEMATIZATION AND USE OF AUDIOVISUAL RESOURCES AS AN KIND OF EXTENSIONIST ACTION}

\begin{abstract}
The implementation of the Marrecas Dam in the Vila Seca district of Caxias do Sul triggered an environmental conflict characterized by the overlapping of traditional occupation and production forms. In this scenario, the present article deals with two objectives: (i) describe and problematize disputes involving the dam; and (ii) build a university extension tool capable of giving visibility to the conflict and strengthening dialogue. To this end, we visited the dam and conducted unstructured interviews with agents from the Serviço Autônomo Municipal de Água e Esgoto, Secretaria Municipal de Agricultura, Pecuária e Abastecimento e affected farmers, a material analyzed in the light of theoretical references pertinent to the theme of environmental conflicts and to university extension. While the first objective was fulfilled, the second, in addition to the relative success in terms of making the conflict visible, ran into financial limitations, making it impossible to monitor and encourage communication between the parties.
\end{abstract}

Keywords: Development. Environmental Question. University Extension.

\section{CONFLICTOS AMBIENTALES Y DESARROLLO RURAL: PROBLEMATIZACIÓN Y USO DE RECURSO AUDIOVISUAL COMO FORMA DE ACCIÓN EXTENSIONISTA}

\section{Resumen}

La implantación del Embalse Marrecas en el distrito Vila Seca, en Caxias do Sul, desencadenó un conflicto ambiental caracterizado por la superposición de las formas de ocupación y producción tradicionales. En este escenario, el presente artículo se ocupó de dos objetivos: (i) describir y problematizar disputas que involucran el embalse; y (ii) construir una herramienta de extensión universitaria capaz de dar visibilidad al conflicto y fortalecer el diálogo. Para ello, visitamos la represa y realizamos entrevistas no estructuradas con agentes del Serviço Autônomo Municipal de Água e Esgoto, da Secretaria Municipal de Agricultura, Pecuária e Abastecimento y agricultores afectados, un material analizado a la luz de referenciales teóricos pertinentes al tema de conflictos ambientales y a la extensión universitaria. Mientras el primer objetivo fue cumplido, el segundo, además del relativo éxito en términos de visibilizar el conflicto, chocó en limitaciones de orden financiero, imposibilitando el acompañamiento y el estímulo a la comunicación entre las partes.

Palabras-clave: Desarrollo. Cuestión Ambiental. Extensión Universitaria. 
Conflitos ambientais e desenvolvimento rural: problematização e uso de recurso audiovisual como auxilio à ação extensionista

\section{INTRODUÇÃO}

Com uma população que ultrapassa os 435 mil habitantes, Caxias do Sul é a segunda maior cidade do Rio Grande do Sul, sendo apenas menos populosa que a capital Porto Alegre (FEE, 2015). O polo metal mecânico, em desenvolvimento desde a metade do século XX, sustentou, e em determinada medida sustenta, o pujante crescimento urbano do município. Embora caracterizada atualmente pela intensa urbanização e industrialização, a história de Caxias do Sul é fortemente calcada no meio rural (RIBEIRO \& MIGUEL, 2012), o qual também foi um dos alicerces do próprio processo de industrialização (SILVA NETO, 2015).

O desenvolvimento industrial, e o consequente aumento da população a partir da década de 1960 (FEE, 2015), tornou mais complexa a zona urbana de Caxias do Sul. Por conta disso, alguns temas passaram a ganhar mais atenção do governo local, sendo a de maior relevância para este estudo aquela que diz respeito ao abastecimento urbano de água. A análise histórica sobre essa questão remota ao ano de 1966, momento de criação do Serviço Autônomo Municipal de Água e Esgoto (SAMAE), autarquia que passou a ser responsável por estudar, projetar e executar direta ou indiretamente obras relativas ao sistema público de abastecimento de água potável e esgoto (SAMAE, 2015).

No que tange ao abastecimento hídrico urbano, após a criação do SAMAE nos anos 1960, iniciaram-se uma série de levantamentos e estudos sobre a construção de barramentos hídricos na zona rural do município, com destaque ao projeto para a apropriação de água do Arroio Faxinal, recurso hídrico localizado no distrito de Vila Seca, de modo que em 1971 se deu início da implantação do que passou a ser chamado de Sistema Faxinal. A concretização dessa obra desapropriou uma área superior a 500 hectares. Dado seu porte, a construção foi realizada em duas partes, a primeira finalizada em 1981 e a complementar concluída em 1992, inaugurando definitivamente o sistema (SAMAE, 2015).

Ainda em 1992, com o Sistema Faxinal em pleno funcionamento, previa-se que o abastecimento de água urbano seria suprido até o ano de 2015, de modo que em 1993 se iniciaram os estudos sobre a possibilidade de construção de mais barramentos em outros mananciais de água. Após as análises, em 2009 são iniciadas as obras de construção de uma nova barragem, agora no Arroio Marrecas, também no distrito de Vila Seca. O Sistema Marrecas passou a funcionar como novo ponto de captação e abastecimento de água da zona urbana a partir do ano de 2012, quando foi inaugurado, tendo inclusive magnitude superior àquela do Sistema Faxinal (SAMAE, 2017). 
Conflitos ambientais e desenvolvimento rural: problematização e uso de recurso audiovisual como auxilio à ação extensionista

Considerando que os dois barramentos estão localizados no mesmo distrito, pode-se inferir que as repercussões de sua construção sobre a população local conformam um quadro sócio-histórico de aproximadamente 45 anos, tempo que tende a ser maior. Considerando a previsão do SAMAE de construir dois novos sistemas de captação em regiões vizinhas a Vila Seca, mais precisamente na exploração das micro bacias Mulada e Sepultura, pareceu relevante problematizar o fato da implantação dessas barragens constar na memória e nas perspectivas de futuro dos sujeitos que residem nessas localidades.

A oportunidade de conhecer a barragem Marrecas e o estimulo à reflexão crítica que sustenta esse artigo é creditado ao Programa de Pós-Graduação em Desenvolvimento Rural da Universidade Federal do Rio Grande do Sul (PGDR/UFRGS), e em especial aos professores da disciplina Problematizando o desenvolvimento rural. A referida disciplina tinha como pressuposto oportunizar aos estudantes o contato com realidades que envolvessem temas rurais contemporâneos como o apresentado. O resultado das experiências vividas deveria subsidiar a construção de uma ferramenta de retorno aos sujeitos que gentilmente nos receberam.

Levando em consideração a magnitude desses empreendimentos, o quadro sóciohistórico introduzido e a oportunidade que tivemos em conhecer a barragem Marrecas e agentes envolvidos, interpretamos o cenário como um conflito ambiental (ACSELRAD, 2004). Instigados pela disciplina estabelecemos dois objetivos, diretamente interligados. O primeiro consistiu em problematizar a realidade encontrada, o que passou por analisar as representações sociais dos agentes envolvidos no conflito ambiental. O segundo, por sua vez, residiu na elaboração de um instrumento de retorno aos sujeitos que conhecemos, onde buscamos apresentar uma visão ampla sobre o cenário em questão e contribuir para o aumento da visibilidade do conflito e o fortalecimento das discussões sobre a problemática em que se encontram inseridos. Esse objetivo culminou na construção de uma ferramenta de extensão universitária.

No que se refere a estrutura desse artigo, além dessa seção introdutória o trabalho se divide em quatro partes. Inicialmente delimitamos o objeto de estudo e descrevemos os aspectos metodológicos que nortearam nossas análises. A seção seguinte se ocupou de problematizar o cenário apresentado e analisar as representações de agentes envolvidos, processo que envolveu a mobilização de referenciais teóricos pertinentes. Essas análises deram subsídios para a seção dedicada a apresentar a ferramenta de extensão universitária construída e compartilhada com os sujeitos entrevistados, material que também se encontra aberto a consulta pública em sítio virtual. Ao fim, em uma breve seção, propomos algumas considerações finais sobre o processo. 
Conflitos ambientais e desenvolvimento rural: problematização e uso de recurso audiovisual como auxilio à ação extensionista

\section{ASPECTOS METODOLÓGICOS}

Para esse artigo, em especial, tomamos como objeto de reflexão o Barramento Marrecas. A construção da problemática se deu através do conhecimento empírico do Barramento e da realização de entrevistas não-estruturadas com uma pequena parcela dos agentes envolvidos, sendo arguidos três diferentes grupos: o primeiro composto por dois representantes do SAMAE, principais promotores e defensores deste projeto; o segundo formado por três agricultores atingidos pelo empreendimento; e por fim, dois representantes da Secretária Municipal de Agricultura, Pecuária e Abastecimento (SMAPA) de Caxias do Sul, que se mostraram os principais mediadores entre os dois primeiros grupos e responsáveis pela promoção de projetos encarados como compensação frente aos efeitos provocados pelo barramento.

Entre os entrevistados foram exploradas questões relacionadas ao processo de implantação da barragem e suas possíveis implicações, bem como alguns aspectos relacionados à relação entre as partes ante e pós execução do projeto. Após o registro das conversas, elas foram organizadas e analisadas a luz de referenciais teóricos pertinentes, visando dar contornos a problemática do conflito ambiental. A partir desse processo, percebemos diferentes representações sociais sobre a relação entre "ser humano" e "natureza", o que entendemos como diferentes quadros interpretativos sobre o conflito ambiental. As entrevistas, o registro e as análises foram realizadas conjuntamente pelos autores.

Como resultado do esforço de problematização e de reflexão sobre a realidade vivenciada, desenvolvemos uma ferramenta audiovisual como instrumento de ação de extensão universitária. O recurso audiovisual consiste num material articulado de fotos e entrevistas realizadas junto a cinco pesquisadores que pudessem, a partir de seus conhecimentos sobre o assunto, contribuir para o fortalecimento das discussões que conformam esse conflito. Tem-se com isso o objetivo de dar visibilidade ao conflito e apresentar um quadro geral sobre o caso em si e conflitos ambientais em geral, a fim de esclarecer e proporcionar um espaço de aproximação entre parte dos sujeitos envolvidos. Reforçamos que, do ponto de vista metodológico, a construção da ferramenta audiovisual deriva justamente do processo de inserção, problematização e reflexão sobre o objeto de estudo.

Após sua elaboração, o vídeo foi entregue aos atores como forma de retorno e concretização da ação de extensão universitária, partindo da perspectiva de extensão "social/acadêmica" tal como apresentada por Verás e Souza (2016). Como procuramos apresentar na seção que se ocupa das considerações finais, além das dificuldades que são inerentes a avaliação de impacto de uma ferramenta como tal num cenário complexo e mutável, 
Conflitos ambientais e desenvolvimento rural: problematização e uso de recurso audiovisual como auxilio à ação extensionista

as dificuldades em termos de recurso tornaram inviáveis as possibilidades de realização de uma avaliação criteriosa com relação aos efeitos que a alternativa proposta obteve. Isso, no entanto, não afeta uma das maiores motivações que tivemos: viabilizar a publicização do conflito ambiental, já que as conversas com os atingidos pela Barragem apontaram um sentimento de impotência quanto a possibilidade de tornar visíveis suas angústias e dificuldades.

O processo completo que levou a esse artigo, o que inclui nossa inserção social, entrevistas com parte dos envolvidos, a problematização do contexto e as análises das perspectivas em jogo, a construção do recurso audiovisual e a entrega aos entrevistados, ocorreu entre o primeiro e o segundo semestre de 2016. A partir desse momento passamos a discutir a possibilidade de apresentar essas reflexões em forma de artigo.

\section{PROBLEMATIZAÇÃO E INTERPRETAÇÕES SOBRE O CONFLITO AMBIENTAL}

Essa seção se ocupa da descrição e da problematização a realidade conhecida. Inicialmente é feita uma breve descrição da configuração desse conflito ambiental e em seguida são apresentados os argumentos de representantes do SAMAE e dos agricultores envolvidos. No decorrer das entrevistas conseguimos perceber diferentes representações sociais sobre a relação entre "ser humano" e "natureza", o que chamamos de quadros interpretativos sobre o conflito ambiental. Logo a seguir destacamos a inserção dos representantes da SMAPA que, como antes citado, são os principais mediadores entre os grupos.

O Sistema Marrecas consiste num barramento hídrico operacionalizado desde 2012 pelo SAMAE. O empreendimento conta com uma área de 489 hectares (ha), sendo 245 ha de terras alagadas e as outras 244 ha destinadas a áreas de "conservação ambiental”. Deste espaço, grandes porções de terra foram adquiridas junto aos produtores que ali residiam, de modo que poucas unidades agrícolas restam no entorno da represa. Ao todo, o empreendimento atingiu 60 agricultores que possuíam propriedades no local de demarcação.

Com capacidade para abastecer cerca de 260 mil pessoas, Marrecas abastece aproximadamente 45 mil nos dias de hoje. Não foram feitas explorações sobre o abastecimento do setor industrial de Caxias do Sul, mas é mister que tal reflexão seja relevante no momento de problematizar o uso dos recursos hídricos deste município. Curiosamente, esta barragem abastece apenas o espaço urbanizado de Caxias do Sul, tendo em vista que o meio rural é abastecido através do uso de poços artesianos. O não abastecimento da área rural no entendimento do SAMAE é atribuído à dispersão das comunidades que habitam o meio rural, o que ampliaria os custos de distribuição e inviabilizaria sua ocorrência. Neste sentido, parece interessante 
Conflitos ambientais e desenvolvimento rural: problematização e uso de recurso audiovisual como auxilio à ação extensionista

questionar os limites da distinção rural-urbano, sendo pertinente apontar, entretanto, sua permeabilidade e interdependência. No caso específico desta barragem, percebe-se que estas localidades tidas como espaço rural acabaram por absorver os impactos socioambientais deste projeto, enquanto o meio urbanizado acabou somente beneficiado com o abastecimento de água.

No que se refere ao processo de implantação desse empreendimento, quando arguidos sobre a aceitação da barragem Marrecas pela população os agentes vinculados ao SAMAE comentaram a negação por parte de "ambientalistas" da região, mas, em sua opinião, " $90 \%$ da população já entendeu esta necessidade". Se percebe na fala de seus propositores que a aceitação do projeto de desenvolvimento por parte da comunidade (atingidos ou não), seria resultado de um contínuo processo de compreensão da necessidade dessa barragem. No entanto, pode-se problematizar essa percepção: tal necessidade, ainda que real para o abastecimento do município, relega a segundo plano as necessidades e interesses dos moradores da região, silenciadas por essa "necessidade maior". Os atingidos pela barragem demonstraram grande frustração por, em suas manifestações de insatisfação, não terem a projeção ou o poder que desejavam. Como desabafa um dos entrevistados e produtor impactado:

Vamos respeitar os homens velhos do cabelo branco que nasceram e tão aí. Eles têm o poder na mão.

Analisando o processo de aquisição das propriedades do entorno da represa, notou-se uma perspectiva de preservação específica. Tal como nas palavras de um entrevistado vinculado ao SAMAE: “é necessário preservar uma área grande sem que as pessoas a habitem”. Torna-se pertinente, portanto, a partir deste e outros relatos semelhantes, problematizar a noção de uma natureza intocada, sem a presença do homem. Nesse sentido, os relatos dos agricultores atingidos e moradores do entorno confirmam essa perspectiva por parte do SAMAE, ao passo que narram o fato de, logo após a demarcação das bacias de captação, o órgão ter passado a estabelecer uma fiscalização ostensiva que impôs à população local a legislação ambiental e a uma rígida normatização, limitando atividades e comprometendo, em certo grau, a possibilidade de reprodução socioeconômica destas famílias. O quadro interpretativo do SAMAE, portanto, concebe a natureza como algo que necessita ser afastada do ser humano como condição para sua preservação.

Sobre a limitação das atividades, quando arguidos sobre a relação que os moradores estabeleciam com seu meio antes da proposição da barragem, um entrevistado citou a realização de pesca, acampamentos e banhos como atividades de lazer dos moradores, mas que com a barragem, "tudo isso terminou", relatou frustrado. Outro entrevistado, na mesma linha, cita o caso de um vizinho, que, ao perceber o nascimento de araucárias em sua propriedade, tão logo os 
Conflitos ambientais e desenvolvimento rural: problematização e uso de recurso audiovisual como auxilio à ação extensionista

cortava. Segundo ele, sabendo das restrições e das futuras complicações, seu vizinho acreditava ser "melhor evitar o transtorno" antes possível. Aqui, nota-se como uma proposta preservacionista, buscando propor a preservação do espaço natural através da desconsideração de sua população e suas formas de interação com o meio - expressão extrema de uma representação que separa "natureza" e "ser humano" - paradoxalmente terminou por gerar um efeito reverso. Mesmo sem intenção de degradar o espaço, a representação expressa pelo SAMAE e as restrições práticas que dela decorrem acabaram fomentando isso.

No que tange à reprodução socioeconômica das famílias, a principal atividade econômica da região é a pecuária extensiva, que por sua vez também é entendida como atividade fundamental para a preservação da paisagem dos campos nativos (AMBROSINI et al., 2012), e por consequência, dos recursos hídricos. Segundo os entrevistados a rigidez da fiscalização tem tendido a dificultar o desenvolvimento dessa atividade. Condizendo com isso, Teixeira (2011) alerta que a rigidez na interpretação das normas bem como a fiscalização ostensiva tem causado problemas socioeconômicos e ambientais nos campos de altitude do Rio Grande do Sul. Essa normatização, ao passo que dificulta a produção de gado de corte em campo nativo, privilegia a produção de monocultivos e altera substancialmente a paisagem, gerando aumento das disparidades socioeconômicas na região. Em síntese, os atingidos demonstram contraposição às proposições do SAMAE, se dizendo frustrados com as restrições que emanam do órgão e afirmando serem portadores de conhecimentos fundamentais para a preservação dos campos nativos, ao passo que seguem realizando práticas semelhantes a seus antepassados. O quadro interpretativo dos atingidos envolvia a defesa de sua valorização como agentes fundamentais para conservação da biodiversidade local.

Refletindo sobre as observações realizadas e os relatos colhidos, notou-se certo antagonismo entre as representações defendidas pelos entrevistados: de um lado, percebeu-se por parte dos representantes do SAMAE uma postura preservacionista que acaba por levar a extremo a separação entre "ser humano" e "natureza" visando a conservação da biodiversidade. Do lado oposto, produtores atingidos demonstram uma perspectiva que reivindica sua necessidade para a conservação desta, em especial em virtude de seus conhecimentos ligados a prática da pecuária em campo nativo. Neste sentido, como aponta Zanoni (2000 p. 41):

Convém situar o preservacionismo no domínio das representações sociais, reveladoras de uma determinada visão de natureza e de intervenção humana sobre a mesma. Neste sentido, o preservacionismo ambiental pode funcionar como uma ideologia, não no sentido de reflexo da realidade, mas [...] como uma forma de agir sobre o real [...]. Se, por um lado, o preservacionismo pode funcionar como ideologia legitimadora de uma dada concepção de natureza e das relações que as sociedades mantêm com a mesma, por outro, é um espaço de representação simbólica onde atuam forças sociais com diferentes projetos de sociedade e de entendimento do papel da natureza. 
Conflitos ambientais e desenvolvimento rural: problematização e uso de recurso audiovisual como auxilio à ação extensionista

Deve-se destacar ainda os impactos que se desdobram das representações promovidas pelo SAMAE, que se evidenciam em restrições de utilização do espaço expressas por exigência de licenciamentos para atividades realizadas nas propriedades, mesmo simples, como, por exemplo, a construção de moradias ou benfeitorias; o decréscimo no valor das terras da região em virtude das restrições estabelecidas para o uso do espaço pela legislação; e, ainda, restrições de circulação humana, incluindo práticas de lazer (banhos nos arroios), pesca e manejo do pinhão, gerando

\footnotetext{
[...] pelas limitações impostas às atividades produtivas no seu âmbito, restrições de uso inadequadas que não levam em conta os interesses reais e [as] representações de natureza [...] [defendidas pelas] comunidades locais (ZANONI, 2000 p. 41).
}

Como sugerem Cunha e Coelho (2005), nesta perspectiva preservacionista os problemas ambientais terminam por enfrentados através da implementação de um conjunto de leis rígidas acerca da forma de uso e acesso à terra e da exclusão de grupos sociais de ecossistemas considerados frágeis e ameaçados, caso da barragem. Diante deste cenário, buscando conciliar a conservação das áreas de produção de água para com a qualificação das condições de vida dos produtores, a partir de um entendimento destes como responsáveis por essa conservação, a Secretaria da Agricultura, Pecuária e Abastecimento (SMAPA) idealizou e executou o Projeto de Preservação das Áreas de Produção de Água nos Distritos de Vila Seca e Criviva, no intuito de preservar áreas de produção de água através da conservação do bioma Mata Atlântica e ecossistema Campos de Altitude, onde se localizam os futuros mananciais para o abastecimento voltado à população urbana, sobretudo à exploração das micro bacias da Mulada e Sepultura.

Esse projeto foi desenhado e executado em dois eixos: (i) melhoramento das pastagens; e, (ii) ações de saneamento básico. A população alvo seriam produtores rurais próximos às micro bacias dos arroios Mulada, Sepultura e Marrecas. Um entrevistado data o surgimento das ideias relativas ao projeto no ano de 2007, justamente em meio às polêmicas sobre a barragem Marrecas e suas inevitáveis repercussões. Segundo ele, a ideia era de "preservar as áreas já preservadas", e não se limitar a ações de recuperação.

Sobre o item "i”, dadas as várias restrições que os produtores passariam a se confrontar em virtude da barragem - pois segundo a ótica de um entrevistado, "dos produtores, só se cobra, se cobra, e não se dá nada em troca" - emergiu a ideia do melhoramento das pastagens nestes distritos, congregando duas variáveis a serem alcançadas: aumento da produtividade e, portanto, da renda destes produtores, e a preservação dos recursos naturais que os mesmos se utilizariam. Para tal, em uma primeira etapa foi demarcada uma área de duas hectares de campo das propriedades selecionadas, onde foram utilizadas técnicas de "melhoramento", isto é, roçadas em 
Conflitos ambientais e desenvolvimento rural: problematização e uso de recurso audiovisual como auxilio à ação extensionista

substituição às queimadas, adubação com fosfato natural, introdução de espécies através do plantio direto e a prática do pastoreio rotativo. Para a implementação do projeto foi disponibilizado, pelo município, os insumos (adubos, corretivo, sementes, arames e eletrificador), bem como as horas das máquinas, equipamentos e a assistência técnica (BRASIL, 2014).

Neste processo, o aporte técnico difundido foi baseado em preceitos técnico-científicos discutidos em circuitos acadêmicos, o que motivou a substituição de práticas antes realizadas, como pastoreio extensivo e queimadas por um pastoreio rotativo e roçadas, por exemplo, incluindo ainda a promoção de práticas como a adubação com fosfato e a introdução de espécies através do plantio direto. Desta forma, foram transplantadas técnicas e saberes a estes agricultores, se mostrando relevante uma problematização da pouca consideração e/ou aceitação do saber-fazer acumulado por eles.

No que tange ao item "iil”, por sua vez, foi proposto o tratamento das águas servidas ao domicílio, instalação de caixa de gordura, de fossa séptica, de filtro anaeróbico e sumidouro, e a construção de esterqueiras para os dejetos dos animais (BRASIL, 2014). Para outra entrevistada, atribuir a importância devida ao saneamento, em detrimento de um foco limitado à dimensão produtiva, seria uma forma de demonstrar que o ato de preservar o é relevante, principalmente, para a condição de vida dos moradores da região, e não apenas por uma suposta necessidade que lhes é externa.

Este projeto foi criado na condição de recompensa aos agricultores que permaneceram na região. Ainda que a ação seja restrita a somente trinta aderentes, a iniciativa parece pertinente ao mobilizar atenção e os recursos direcionados para a melhoria de renda destes produtores e a conservação dos campos nativos. Cabe ressaltar que, na ausência de outras formas de mediação, como a atuação de movimentos sociais, por exemplo, os funcionários da SMAPA acabam sendo os principais mediadores e defensores dos interesses desses agricultores.

Diferente da representação externada pelo SAMAE, a SMAPA reconhece o papel exercido por estes produtores, ainda que, no entanto, tal consideração não tenha implicado na efetiva participação da população no processo de idealização e implementação do projeto, o que em grande medida ajuda a explicar a pouca adesão dos produtores da região. De modo geral, os produtores entrevistados junto a mediação exercida por agentes da SMAPA parecem ser gratos aos esforços realizados pelos agentes, defensores de seus interesses, mesmo que constrangidos e subordinados ao interesse maior: o funcionamento da barragem e o suposto desenvolvimento do município de Caxias do Sul.

Quanto às restrições vividas pelos agricultores, uma entrevistada é clara: "eles vêm aqui e dizem que é [questão de] utilidade pública [...], e se eu fosse na casa de vocês e dissesse para 
Conflitos ambientais e desenvolvimento rural: problematização e uso de recurso audiovisual como auxilio à ação extensionista

saírem por utilidade pública?”. Alguns parecem pagar pelos benefícios de outros. Estaríamos diante de um nó górdio? Como equacionar interpretações distintas e, infelizmente, contrastantes e excludentes? Essa constatação coloca em xeque o uso dos recursos hídricos de Caxias do Sul e o modelo de desenvolvimento em jogo. Como deveríamos atuar diante da realidade aqui apresentada? Como contribuir para as discussões ou, ao menos, dar visibilidade ao conflito ambiental? A alternativa encontrada, que envolve a construção e difusão de uma ferramenta audiovisual que apresente temas afins ao assunto, é apresentada e discutida na seção seguinte.

\section{FERRAMENTA DE EXTENSÃO UNIVERSITÁRIA}

Para Véras e Souza (2016) podem ser percebidas no Brasil três perspectivas da ação universitária, sendo essas, a assistencialista, a mercantilista e a social/acadêmica. Não entrando na discussão das outras duas concepções, segundo os autores, é o viés social/acadêmico que possibilita realização, por parte das a universidades, do seu compromisso com a sociedade. Nesta concepção o conhecimento universitário deve procurar estabelecer um conhecimento dialógico com seus interlocutores, onde a Universidade, imbuída de seu caráter social e educativo, articula o ensino e a pesquisa como responsáveis pela produção e pela gestão de conhecimento, cabendo a extensão articular, de forma dialógica, a complexa relação entre Academia e Comunidade (TOSCANO \& SANTOS JÚNIOR 2013).

Embora em termos teóricos, a perspectiva a qual deve orientar a extensão universitária seja relativamente clara, o estabelecimento dessa relação dialógica na atividade prática torna-se complexa e em muitos casos de difícil desenvolvimento, acabando por colocar em risco sua efetividade (MACHADO et al., 2015), impondo aos pesquisadores a busca de inovações na realização desta prática (SILVA NETO, 2009). Considerando a necessidade de estabelecimento de uma extensão universitária dialógica e mobilizadora dos atores sociais, bem como inovadora no sentido de se estabelecer com uso prático e facilmente apropriada pela sociedade, vimos na construção de um vídeo que articulasse descrições e análises de pesquisadores sobre o tema em questão uma alternativa pouco custosa e de fácil difusão para nossos propósitos, isto é, visibilizar o conflito ambiental em questão e estimular os debates sobre esse e outros empreendimentos futuros.

Para tanto, na construção do vídeo foram articulados cinco eixos temáticos de discussão, sendo estes relacionado a (i) caracterização de conflito ambiental; (ii) relação sociedade/natureza; (iii) conservação e preservação; e seus desdobramentos em (iv) questões práticas; e (v) questão indenitária dos 
Conflitos ambientais e desenvolvimento rural: problematização e uso de recurso audiovisual como auxilio à ação extensionista

agentes e sua relação com o meio em conflito. No Quadro 1 um são apresentas, resumidamente, as questões tratadas e os objetivos de cada eixo temático.

Quadro 1: Questões e objetivos dos cinco eixos temáticos articulados na ferramenta audiovisual.

\begin{tabular}{|l|l|l|}
\hline \multicolumn{1}{|c|}{ Eixo Temático } & \multicolumn{1}{|c|}{ Questões abordadas } & \multicolumn{1}{c|}{ Objetivo Central } \\
\hline $\begin{array}{l}\text { (i) caracterização de conflito } \\
\text { ambiental }\end{array}$ & $\begin{array}{l}\text { Características e singularidades } \\
\text { dos conflitos ambientais. }\end{array}$ & $\begin{array}{l}\text { Instigar a percepção dos atores do conflito } \\
\text { ambiental no qual se encontram inseridos. }\end{array}$ \\
\hline (ii) relação sociedade/natureza & $\begin{array}{l}\text { Hegemonia da racionalidade } \\
\text { científica e sua relação com a } \\
\text { separação da sociedade com seu } \\
\text { meio (natureza). }\end{array}$ & Embasar, em termos teóricos, o eixo iii. \\
\hline $\begin{array}{l}\text { (iii) conservação e preservação } \\
\text { Separação entre sociedade e } \\
\text { satureza e consequente impacto a definição de conservação } \\
\text { e preservação. }\end{array}$ & $\begin{array}{l}\text { Demonstrar que o cerne do conflito ambiental } \\
\text { em questão, é decorrência das próprias } \\
\text { interpretações sobre sociedade e natureza e } \\
\text { das noções de conservação e preservação. }\end{array}$ \\
\hline $\begin{array}{l}\text { (iv) questões práticas } \\
\text { Diversidade e importância do } \\
\text { manejo do campo nativo. }\end{array}$ & $\begin{array}{l}\text { Subsidiar elementos acadêmicos aos atores da } \\
\text { importância da relação entre as atividades } \\
\text { humanas para a própria conservação e } \\
\text { manutenção do ambiente. }\end{array}$ \\
\hline $\begin{array}{l}\text { (v) questão indenitária dos } \\
\text { agentes e sua relação com o } \\
\text { meio em conflito }\end{array}$ & Identidade regional & $\begin{array}{l}\text { Estender aos atores o debate em torno da } \\
\text { identidade regional }\end{array}$ \\
\hline
\end{tabular}

Fonte: Elaborado pelos autores.

A caracterização do conflito ambiental foi um eixo principal, onde tratou-se de forma objetiva da ideia de conflitos ambientais, das características comuns e das singularidades de situações como como estas. Tal caracterização teve como objetivo fundamental estender aos interlocutores que a situação analisada pode ser concebida como um conflito ambiental, uma vez que como tratado por Sigaud (1986) e Freitas (2015), não necessariamente conflitos ambientais são reconhecidos de forma clara pelos atores envolvidos. Esse eixo de discussão contou com a entrevista de uma professora e pesquisadora a qual desenvolve estudos e trabalhos com a temática de conflitos ambientais.

Já o segundo eixo, que tratou das diferentes implicações da relação entre sociedade e natureza, teve como objetivo central embasar o eixo (iii) “conservação e preservação". Desse modo fez se uma discussão introdutória associada ao raciocínio explorado por Raynout (2014) e Almeida \& Premebida (2014), o qual expõem que o avanço dos paradigmas que movem a sociedade moderna, calcados principalmente sobre racionalidade científica e mecanicista, corroboram em uma separação entre a "sociedade" e seu entorno, a "natureza". Por meio de uma explanação didática sobre a questão se objetivou estender aos interlocutores que esta separação 
Conflitos ambientais e desenvolvimento rural: problematização e uso de recurso audiovisual como auxilio à ação extensionista

em seu limite acaba por definir as noções de conservação e preservação, e que são cernes da questão ambiental, e por consequência, do próprio conflito ambiental no qual estão inseridos. Para esse eixo fez-se uma entrevista com pesquisador dedicado à temática das representações sobre sociedade e natureza. Se objetivou no material audiovisual demonstrar que o limite interpretativo da divisão entre sociedade natureza acaba por imprimir uma lógica estritamente preservacionista onde, como salientado por Freitas (2015), interpreta natureza como um espaço intocável, em que as áreas naturais "protegidas" deveriam permanecer intactas, por se acreditar na incompatibilidade de qualquer tipo de ação humana com conservação da natureza, sendo o ser humano considerado um "vilão" a ser mantido afastado dessas áreas naturais.

Esses três eixos iniciais, que compõe a primeira parte do vídeo, procuraram articular as interpretações acadêmicas de como o conflito ambiental se conforma e quais suas sustentações. Os dois eixos seguintes articularam as implicações em questões práticas dessa conformação, uma vez que a região de ocorrência do conflito se dá na região dos Campos de Cima da Serra, a qual de acordo com Ambrosini et al. (2012) tem seus sistemas produtivos amplamente baseados na pecuária extensiva e no manejo antrópico do campo nativo.

Assim, o eixo (iv) procurou destacar a importância da relação entre as atividades humanas para a própria conservação e manutenção do ambiente, em contraponto a visão preservacionista mais radical. Desse modo, para estabelecer o diálogo com os interlocutores foram feitas entrevistas com três pesquisadores da área da botânica os quais se dedicam ao estudo da diversidade e da importância do manejo do campo nativo. Esse eixo foi considerado central a ser estendido aos atores, uma vez que pode dar subsídios acadêmicos, ainda que superficiais, para um ponto chave do conflito ambiental, que em última análise, passa fundamentalmente pela apropriação e uso do ambiente. O quinto eixo temático entrevistou pesquisadora a qual já vem trabalhando questões relacionadas a identidade da região, sendo que se teve como objetivo a possibilitar a ampliação e até mesmo o conhecimento por parte dos atores dessa temática. Por fim, foram feitas algumas considerações fomentando a necessidade de diálogo entre as partes quando se tratando de relações conflituosas.

Cabe destacar que o vídeo foi enviado aos sujeitos que conhecemos e encontra-se disponível no seguinte endereço virtual:

https://www.youtube.com/watch?v=r4RKxdpvv3M\&feature=youtu.be (URL curto: https://goo.gl/msmvKQ 
Conflitos ambientais e desenvolvimento rural: problematização e uso de recurso audiovisual como auxilio à ação extensionista

Ainda que não seja possível reparar os impactos negativos já causados pela implantação da barragem Marrecas, com esta proposta acredita-se que seja possível dar projeção para o caso em questão e viabilizar o fortalecimento da discussão. Isso nos parece necessário ao passo que, segundo projetado pelo SAMAE, continuarão a ser operacionalizados novos barramentos no intuito de manter o abastecimento de água da região urbana do município de Caxias do Sul, com destaque aos já idealizados barramentos das micro bacias Mulada e Sepultura.

\section{CONSIDERAÇÕES FINAIS}

$\mathrm{Na}$ introdução desse artigo nos comprometamos com dois objetivos. O primeiro envolvia a descrição e a problematização do processo e das disputas que envolvem a implantação do Barramento Marrecas. Essas análises dariam subsídios para o segundo objetivo traçado, a construção de uma ferramenta para a ação de extensão universitária que pudesse contribuir para a visibilidade desse conflito ambiental e o fortalecimento das discussões sobre a problemática em que se encontram inseridos. Chegou o momento de ponderar sobre o percurso trilhado e como, dentro do possível, cumprimos os objetivos traçados.

No que tange ao primeiro, sua concretização se expressa nos argumentos que propomos ao longo da seção Problematização e interpretações sobre o conflito ambiental. A partir da mobilização de referências teóricas percebemos que esse conflito se processa, em boa medida, em virtude do confronto entre diferentes representações da relação ser humano/natureza. Refletindo sobre as observações realizadas e os relatos colhidos, notou-se certo antagonismo entre as representações defendidas pelos entrevistados: de um lado, percebeu-se por parte dos representantes do SAMAE uma postura preservacionista que acaba por separar o "ser humano" da "natureza" e culmina com uma rígida normatização para a população atingida, dificultando por conseguinte tanto a reprodução socioeconômica quanto hábitos cotidianos relacionadas ao bem-estar das famílias que ainda residem nesta localidade, e isto em grande medida por desconsiderar seus saberes para a conservação dos territórios e suas raízes à localidade; e por outro, os produtores atingidos demonstram uma perspectiva que reivindica sua necessidade para a conservação da biodiversidade da região, especialmente em virtude de seus conhecimentos ligados a prática da pecuária em campo nativo. Esses saberes, no entanto, em projeto orientado aos atingidos pela barragem, passaram a ser questionadas por funcionários da SMAPA, que paradoxalmente são os maiores defensores dos interesses dos sujeitos impactados pelo conflito ambiental.

A partir desse momento passamos a nos perguntar como poderíamos contribuir para equacionar interpretações distintas e, infelizmente, contrastantes e excludentes? Após deliberar 
Conflitos ambientais e desenvolvimento rural: problematização e uso de recurso audiovisual como auxilio à ação extensionista

vimos na construção de um vídeo que articulasse descrições e análises de pesquisadores sobre o tema discutido uma alternativa pouco custosa e de fácil difusão para nossos propósitos, como descrito na seção Ferramenta de extensão universitária. Dado a dificuldade do estabelecimento de diálogo em situações de conflitos tal como a problematizada, a utilização de ferramentas inovadoras, como as audiovisuais, pode trazer benefícios ao conjunto dos envolvidos pois possibilitam a exposição de informações e mensagens de forma clara e acessível, a ser facilmente apropriada como modo de intervenção da realidade, podendo subsidiar discussões entre os atores envolvidos. Além disso, por articular discursos de respaldo acadêmico, pode servir como contraponto a discursos conservadores e já pragmáticos os quais tendem a estar presentes em disputas políticas e territoriais.

Entretanto, estamos cientes de nossas limitações. Se por um lado é possível destacar que a ferramenta construída foi uma contribuição metodológica para a extensão universitária, uma vez que a mesma pode ser considerada como um instrumento de conscientização ou alternativa interpretativa para situações que não são evidentes para todos envolvidos, por outro, considerando o complexo jogo de inter-relações que conformam esses conflitos e as limitações em termos de recursos financeiros que tivemos interferiu na possibilidade de realização de uma avaliação mais criteriosa com relação aos efeitos que a alternativa proposta obteve, já que essa situação acabou restringindo nossa atuação em termos de acompanhamento e estímulo à comunicação entre as partes. Entretanto, isso não afetou uma de nossas maiores motivações: aumentar a visibilidade desse conflito ambiental, tendo em vista que as conversas com agricultores atingidos pelo conjunto de barramentos apontaram um sentimento de impotência quanto a possibilidade de tornar visíveis suas angústias e dificuldades. Essas questões permanecem abertas a análises críticas que possam contribuir à compreensão do conflito ambiental e, se possível, à redução das insatisfações entre as partes.

\section{AGRADECIMENTOS}

Agradecemos aos colegas Eduardo Hernandes Dutra e Mirian Fabiane Dickel Strate pela enorme contribuição na realização das entrevistas e na edição do recurso audiovisual produzido. O mesmo sentimento vale para a professora Rumi Regina Kubo, parceira no processo. 
Conflitos ambientais e desenvolvimento rural: problematização e uso de recurso audiovisual como auxilio à ação extensionista

\section{REFERÊNCIAS}

ALMEIDA, Jalcione; PREMEBIDA, Adriano. Apresentação do Dossiê: Histórico, relevância e exploração antológicas da questão ambiental. Sociologias v. 16 n. 35: 14-33. 2014.

ACSELRAD, Henri. As práticas espaciais e o campo dos conflitos ambientais. In: Conflitos Ambientais no Brasil. Rio de Janeiro: Relume-Dumará: Fundação Heinrich Böll. 2004. p. 1334.

AMBROSINI, Larissa; MIGUEL, Lovois de Andrade; FILIPPI, Eduardo Ernesto. Evolução e diferenciação dos sistemas agrários nos Campos de Cima da Serra: origem dos pecuaristas familiares produtores do Queijo Serrano. Desenvolvimento e Meio ambiente (UFPR), v. 26, p. 171-187, 2012.

BRASIL. Prêmio ANA 2014: Preservação das Áreas de Produção de Água nos Distritos de Vila Seca e Criúva, 2015. Disponível em: $<$ http://premio.ana.gov.br/Edicao/2014/projetodetalhe.aspx?id=33\&\$ListID=A2CB8C6D-6FE2-4E67-BD57-5254DBCF88DD $>$. Acesso em 11 jul 2016.

CUNHA, Luis Henrique; COELHO, Maria Célia. Política e Gestão Ambiental. In: CUNHA, Sandra; GUERRA, Antônio José (org.). A questão ambiental: diferentes abordagens. Rio de Janeiro: Bertrand Brasil, 2a ed., 2005, p. 43-79.

FREITAS, Márcio Antônio Farias. Etnografia de uma caminhada ecológica em meio à paisagem hibrida da ilha. Caderno eletrônico de Ciências Sociais, v. 2, n. 2, p. 71-86. 2014.

FEE, Fundação de Economia e Estatística. Municípios 2010. Disponível em: < http://www.fee.rs.gov.br/perfilsocioeconomico/coredes/detalhe/?corede $=$ Fronteira $+\mathrm{N}$ oroeste> Acesso em: 01 out 2016.

MACHADO, José Tobias Marks; TONIN, Jeferson; SCHNEIDER, Evandro Pedro. Análise de ações extensionistas a partir de hortas escolares de base ecológica, seus efeitos e desafios no contexto educacional. Revista Brasileira de Extensão Universitária, v. 6, n. 2, p. 97-101, 2015.

RIBEIRO, Claudia; MIGUEL, Lovois de Andrade. Evolução e Diferenciação de Sistemas Agrários: o caso do distrito de Vila Seca - Caxias do Sul/ RS. In: CONGRESSO BRASILEIRO DE SISTEMAS DE PRODUÇÃO. 9, 2012, Brasília. Anais (...) Brasília, UNB: 2012.

RAYNAUT, Claude. Meio Ambiente e Desenvolvimento: construindo um novo campo do saber a partir da perspectiva interdisciplinar. Desenvolvimento e Meio Ambiente, n. 10, p. 21-32, 2014. 
Conflitos ambientais e desenvolvimento rural: problematização e uso de recurso audiovisual como auxilio à ação extensionista

TEIXEIRA, Bruno Moraes. Proibição da queima de campo, solução ou problema? Impactos socioeconômicos e ambientais no município e São Francisco de Paula, RS, 2011. Trabalho de Conclusão de Curso (Tecnólogo em Planejamento e Gestão para o Desenvolvimento Rural). UFRGS, 2011, 86 p.

SAMAE, Serviço Autônomo Municipal de Água e Esgora. Samae 50 anos: Serviço Autônomo Municipal de Água e Esgoto de Caxias do Sul. Caxias: Município de Caxias do Sul. 2015.

· Histórico, 2016. Disponível em: < http://www.samaecaxias.com.br/Pagina/Index/6>. Acesso em: 09 out 2016.

SIGAUD, Lygia. Efeitos sociais de grandes projetos hidrelétricos: as barragens de Sobradinho e Machadinho. Programa de Pós-Graduação em Antropologia Social, Museu Nacional - UFRJ, 1986.

SILVA NETO, Benedito. A regionalização do Estado segundo seus Sistemas Agrários. In: __ _ BASSO, David (Org.) Sistemas Agrários do Rio Grande do Sul: Análise e Recomendações de Políticas. Ijuí: Editora UNIJUÍ, 2015, p. 93-108.

SILVA NETO, Benedito. A Agronomia e o Desenvolvimento Sustentável: Por uma Ciência da Complexidade. Desenvolvimento em Questão n.7 v. 1., 2009.

SOUZA, Gabriela Coelho et al. Novos Territórios Rurais no Rio Grande do Sul: os Campos de Cima da Serra e Litoral e suas microrregiões. In: SEMINÁRIO OBSERVATÓRIOS. 5, 2015, São Leopoldo. Anais (...) São Leopoldo, Unissinos, 2015.

TOSCANO, Geovânia da Silva; SANTOS JÚNIOR, Alcides Leão. A formação universitária e gestão acadêmica no ensino público: experiências de ações extensionistas na UFRN e na UFBA. Revista Temas em Educação, v. 22, n. 2, p. 171-190, 2013.

VÉRAS, Renata Meira; SOUZA, Gezilda Borges de. Extensão universitária e atividade curricular em comunidade e em sociedade na Universidade Federal da Bahia. Revista Brasileira de Extensão Universitária, v. 7, n. 2, p. 83-90, 2016.

ZANONI, Magda. Preservação da natureza e desenvolvimento rural: dilemas e estratégias dos agricultores familiares em Áreas de Proteção Ambiental. Desenvolvimento e Meio Ambiente, n. 2. p. 39-55, jul-dez, 2000. 